\title{
Tensile and erosive strength of soil macro-aggregates from soils under different management system
}

\author{
Emilia Urbanek $^{1,2^{*}}$, Rainer Horn², Alwin J.M. Smucker ${ }^{2,3}$ \\ ${ }^{1}$ Royal Society Research Fellow, Swansea University, College of Science, Department of Geography, Singleton Park, Swansea, UK. \\ ${ }^{2}$ Institute for Plant Nutrition and Soil Science, Christian-Albrechts-University of Kiel, Kiel, Germany. \\ ${ }^{3}$ Department of Plant, Soil and Microbial Sciences, Michigan State University, East Lansing, Michigan, USA. \\ * Corresponding author. E-mail: e.urbanek@swansea.ac.uk
}

\begin{abstract}
Reduced soil tillage practices are claimed to improve soil health, fertility and productivity through improved soil structure and higher soil organic matter contents. This study compares soil structure stability of soil aggregates under three different tillage practices: conventional, reduced and no tillage. The erosive strength of soil aggregates has been determined using the abrasion technique with the soil aggregate erosion chambers (SAE). During abrasion soil aggregates have been separated into the exterior, transitional and interior regions. The forces needed to remove the material from the aggregate were calculated as erosive strength and compared with the tensile strength of the aggregates derived from crushing tests. The relationship between aggregate strength and other soil properties such as organic carbon and hydrophobic groups' content has also been identified.

The results show that erosive and tensile strength of soil aggregates is very low in topsoil under conventional and reduced tillage comparing with the subsoil horizons. Negative correlation was found between the content of organic carbon, hydrophobic compounds and erosive aggregate strength which suggests that the stabilising effect of soils organic carbon may be lost with drying. The positive relationship between the tensile strength and erosive strength for aggregates of $8-5 \mathrm{~mm}$ size suggests that the total strength of these aggregates is controlled by the sum of strength of all concentric layers.
\end{abstract}

Keywords: Tensile strength; Erosive strength; Exterior/interior aggregate region; Aggregate; Concentric layers; Dry aggregate stability; Reduced tillage.

\section{INTRODUCTION}

Soil tillage practices have been claimed as a main reason for the loss of soil organic carbon (SOC) in soils and it is strongly believed that the SOC sequestration can be achieved by application of less destructive tillage practices (Holland, 2004). Other benefits of reduced tillage practices include improved soil structure and water retention, protection against erosion and overall reduction of the production cost. Several studies have shown that incorporation of the reduced or no tillage practices benefits the soil health, fertility and productivity (Lal, 2003). Such structurally stable soils are able to withstand external stresses originating from natural or human processes and maintain a structural state that permits a good transport of water, gas and nutrients but also allow a root development and plant growth. A few studies have shown that depending on soil management, the soil structure re-formation can be affected and together with the hierarchical soil aggregate formation some soil aggregates develop layers within aggregates (Park and Smucker, 2005c; Santos et al., 1997; Urbanek et al., 2007, 2011). The aggregate layers develop from the exterior to the interior of the aggregate due to preferential flow of water and nutrient. The gradients in soil aggregates include changes in porosity, particle size distribution, hydraulic conductivity, carbon mineralization (Park and Smucker, 2005a; Park and Smucker, 2005c; Urbanek et al., 2007), nutrient content and microbial activity gradient (Jasinska et al., 2006). Recent X-ray computer tomography techniques, which allow the nondestructive observation of internal aggregate structure, have partly confirmed the hypothesis about formation of gradients in soil structure along the preferential flow paths (Ananyeva et al., 2013; Wang et al., 2012).
The stability of soil structure and soil aggregates is strongly linked with physical protection of soil organic matter within soil aggregates (Bachmann et al., 2008; von Lützow et al., 2006). Physical separation of the soil organic matter usually concentrated in the interior of the aggregate from the decomposing microorganisms which are mainly on the aggregate external surfaces has been claimed as one of the very important stabilisation mechanisms. The stability of aggregates depends on the strength of intra-aggregate bonds and distribution of possible failure zones related to the geometries of air filled pores, small cracks, strength of mineral-organic bonds, and other cementing agents between soil particles (Bronick and Lal, 2005; Kodešová et al., 2009a). The distribution and resistance of these failure zones contribute to the dynamic physical characteristics controlling soil responses to cultivation, rain drop energies, root growth, and other applied stresses.

Several studies reported positive effects of total organic matter (OM) (Abiven et al., 2009; Bronick and Lal, 2005; Tisdall and Oades, 1982) on structure stability, whereas others indicated that the composition of OM (especially the humified fractions) rather than the total amount per se is responsible for aggregate stabilization (Dutarte et al., 1993). Organic matter can decrease soil wettability and hydrophobic organic coating can prevent water from infiltrating into the aggregates or at least reduce their rates of wetting thereby contributing to their stability (Bachmann et al., 2008; Chenu et al., 2000). Capriel et al. (1990) reported good correlations between the hydrophobic aliphatic $(\mathrm{C}-\mathrm{H})$ fraction in soil and its aggregate stability. Similarly Piccolo and Mbagwu (1999) showed that hydrophobic organic matter is more effective and long-lasting for aggregate binding than the hydrophilic OM such as root exudates or polysaccharides of plant tissues. In our study we have aimed to 
separate the hydrophobic aliphatic fraction of soil aggregate layers and relate it to cementing effect at each particular layer of soil aggregates from exterior to the interior. The separation of uniform concentric layers of aggregates using soil aggregate erosion chambers has been first proposed by Santos et al. (1997) and during the separation of the material the time of erosion was measured. They found that abrasion of soil aggregates varies in time. Thus, Park and Smucker (2005b) proposed the calculation of the erosive strength of single aggregates. They defined the erosive strength $\left(E_{s}\right)$ as erosive forces required to remove $1 \mathrm{~g}$ of soil during 1 minute from the surface of a soil aggregate rotating along the abrasive wall within each SAE chamber. They investigated the aggregates from conventional, conservation tillage and forest soil from topsoil and found differences in erosion strength between them.

Thus, the objective of this study is to identify the erosive strength of different concentric layers of aggregates, to compare the tensile and erosion strength of aggregates from different soil management and soil depths, and to find a relationship between aggregate strength and other soil properties like organic carbon and hydrophobic organic matter group's content.

\section{MATERIAL AND METHODS Soil material}

Soil samples from sites under three different management systems were collected from experimental fields at Rotthal- münster in southern Germany (Table 1). The sites were under the following management systems: (1) soil under conventional tillage planted with maize soil as monoculture for 24 years; (2) soil under reduced tillage for 6 years with wheat vegetation soil for 34 years; and (3) soil under no tillage under grassland vegetation (for 43 years). The soils are classified as Hortic Anthrosols and Haplic Luvisol according to WRB (2006) (Table 1) and are all silty loam in texture (Urbanek et al. 2007). General properties of the analysed soil have been presented in the Table 1 and details of the methodology used to determine the general properties are published by Urbanek et al. (2007).

At each site, large blocks of soil $(\sim 30 \mathrm{~cm} \times 30 \mathrm{~cm} \times 40 \mathrm{~cm})$ were excavated from three depths, which corresponded to soil horizons, and transported to the laboratory in a field moist condition (water content $\sim 30 \%$ by mass). Soil aggregates were separated from the bulk soil by manually breaking the bigger blocks along planes of weakness in a moist condition. After airdrying, the aggregates were manually sieved into the following seven size fractions: $15-12 \mathrm{~mm} ; 12-8 \mathrm{~mm} ; 8-5 \mathrm{~mm} ; 5-2 \mathrm{~mm}$; $2-1.25 \mathrm{~mm} ; 1.25-0.63 \mathrm{~mm} ; 0.63-0.125 \mathrm{~mm}$ diameter. The aggregate size distribution (Table 2) of soils under different tillage systems shows that the aggregates size classes between $12-8 \mathrm{~mm}, 8-5 \mathrm{~mm}$ and $5-2 \mathrm{~mm}$ constitute the majority of the aggregate by mass therefore the measurements of the tensile strength have been focused only on these selected size classes while the erosive strength of aggregates was determined only on $12-8 \mathrm{~mm}$ and $8-5 \mathrm{~mm}$ aggregates.

Table 1. General description of analysed soil under various soil management types.

\begin{tabular}{|c|c|c|c|c|c|c|c|c|c|c|c|}
\hline \multirow{2}{*}{$\begin{array}{l}\text { Soil } \\
\text { management } \\
\text { type }\end{array}$} & \multirow{2}{*}{$\begin{array}{l}\text { Vegetation } \\
\text { type }\end{array}$} & \multirow{2}{*}{ Soil type* } & \multirow{2}{*}{$\begin{array}{l}\text { Soil depth } \\
\text { (cm) }\end{array}$} & \multirow{2}{*}{$\begin{array}{c}\text { Soil } \\
\text { horizon }\end{array}$} & \multicolumn{3}{|c|}{ Texture (\%) } & \multirow{2}{*}{$\begin{array}{c}\mathrm{pH}\left(\mathrm{CaCl}_{2}\right) \\
(-)\end{array}$} & \multirow{2}{*}{$\begin{array}{l}\text { Corg } \\
(\%)\end{array}$} & \multirow{2}{*}{$\begin{array}{l}\mathrm{N} \\
(\%)\end{array}$} & \multirow{2}{*}{$\begin{array}{l}\mathrm{C} / \mathrm{N} \\
(-)\end{array}$} \\
\hline & & & & & Sand & Silt & Clay & & & & \\
\hline \multirow{3}{*}{$\begin{array}{l}\text { Conventional } \\
\text { tillage }\end{array}$} & \multirow{3}{*}{$\begin{array}{c}\text { Maize } \\
\text { (24 years) }\end{array}$} & \multirow{3}{*}{$\begin{array}{c}\text { Hortic } \\
\text { Anthrosol }\end{array}$} & $0-15$ & Ap1 & 10 & 68 & 22 & 6.4 & 1.4 & 0.14 & 10.1 \\
\hline & & & $15-35$ & Ap2 & 10 & 69 & 21 & 6.2 & 1.3 & 0.14 & 9.6 \\
\hline & & & $35-45$ & Sw-M & 7 & 72 & 21 & 6.0 & 0.6 & 0.08 & 7.9 \\
\hline \multirow{3}{*}{ Reduced tillage } & \multirow{3}{*}{$\begin{array}{l}\text { Wheat } \\
\text { (34 years) }\end{array}$} & \multirow{3}{*}{ Haplic Luvisol } & $0-20$ & Ap1 & 9 & 68 & 23 & 6.4 & 1.4 & 0.15 & 9.1 \\
\hline & & & $20-32$ & $\mathrm{rAp}$ & 9 & 66 & 26 & 6.3 & 1.1 & 0.13 & 8.5 \\
\hline & & & $32-45$ & $\mathrm{Bt}$ & 7 & 65 & 28 & 6.2 & 0.5 & 0.07 & 7.5 \\
\hline \multirow{3}{*}{ No tillage } & \multirow{3}{*}{$\begin{array}{l}\text { Grassland } \\
\text { (43 years) }\end{array}$} & \multirow{3}{*}{$\begin{array}{c}\text { Hortic } \\
\text { Anthrosol }\end{array}$} & $0-13$ & $\mathrm{Ah}$ & 7 & 70 & 23 & 3.3 & 1.6 & 0.17 & 9.4 \\
\hline & & & $13-28$ & $\mathrm{rAp}$ & 9 & 71 & 21 & 3.8 & 0.8 & 0.11 & 7.9 \\
\hline & & & $28-39$ & Sw-M & 8 & 72 & 21 & 4.5 & 0.6 & 0.08 & 7.7 \\
\hline
\end{tabular}

* According to WRB (2006).

Table 2. Aggregate size distribution (mass \%) of soils under different management type and soil horizon.

\begin{tabular}{lccccccccc}
\hline \multirow{2}{*}{$\begin{array}{c}\text { Aggregate size } \\
(\mathrm{mm})\end{array}$} & \multicolumn{3}{c}{ Conventional tillage } & \multicolumn{3}{c}{ Reduced tillage } & \multicolumn{3}{c}{ No tillage } \\
\cline { 2 - 10 } \multicolumn{1}{c}{} & Ap1 & Ap2 & Sw-M & Ap & rAp & Bt & Ah & rAp & SW-M \\
\hline$>12$ & 26 & 42 & 22 & 20 & 52 & 9 & 33 & 44 & 41 \\
$12-8$ & 20 & 18 & 41 & 29 & 19 & 52 & 24 & 25 & 31 \\
$8-5$ & 12 & 13 & 16 & 21 & 12 & 19 & 17 & 13 & 15 \\
$5-2$ & 17 & 15 & 13 & 18 & 11 & 13 & 15 & 12 & 10 \\
$2-1.25$ & 8 & 5 & 4 & 4 & 3 & 3 & 5 & 3 & 2 \\
$1.25-0.63$ & 7 & 4 & 2 & 3 & 2 & 2 & 3 & 2 & 1 \\
$0.63-0.125$ & 6 & 3 & 1 & 2 & 1 & 1 & 3 & 1 & 1 \\
$<0.125$ & 3 & 0.8 & 0.4 & 2 & 0.6 & 0.6 & 1 & 0.3 & 0.4 \\
\hline
\end{tabular}




\section{Separation of aggregate layers}

Air-dried soil aggregates of $12-8 \mathrm{~mm}$ and $8-5 \mathrm{~mm}$ diameter size were separated to three different regions: exterior, transitional and interior (Fig. 1). The external aggregate layer corresponded to $25 \%$ of abraded mass of the aggregate, $25-50 \%$ and $50-75 \%$ was the transitional region and the rest was the aggregate interior. The separation of the material from each layer was conducted using the soil aggregate erosion chambers (Fig. 2a) which have knurled inside wall to abrade surface material during horizontal rotary shaking (Park and Smucker, 2005b; Urbanek et al., 2007, 2011). The abraded material was separated by a screen and collected at the base of the chamber. Removal of the abraded soil material at regular time intervals allowed determination of the properties for each aggregate layer and calculation of the soil aggregate mass being abraded during specific time. The abraded material from each aggregate layer have been separately analysed for organic carbon content (Corg) using the continuous flow mass spectrophotometer consisting of an ANCA SL sample converter attached to a 2020 IRMS (Europa Scientific, Crewe, UK). The content of hydrophobic C-H groups in soil was determined using Diffuse Reflectance Infrared Fourier Transform (DRIFT) spectrometer and the details of the methodology have been provided by Urbanek et al. (2007).

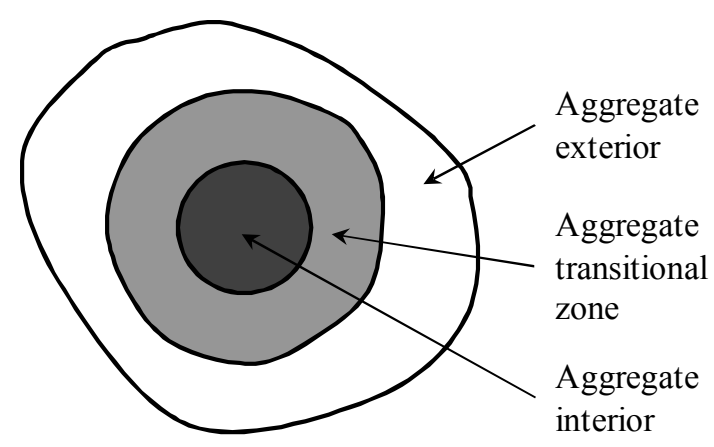

Fig. 1. Concentric layers of soil aggregate: exterior, transitional and interior.

\section{Determination of aggregate erosive strength $\left(E_{s}\right)$}

Using the soil aggregate erosion (SAE) chamber the multiple concentric layers were removed from individual aggregates and the applied forces were determined to calculate the erosion strength of single aggregates. To remove the soil material from the surface of each aggregate the external applied force must have been higher than the internal resistant strength of the aggregate. The quantity of eroded soil material from each aggregate layer is proportional to the difference between external erosive forces and internal resistance or erosive strength (Park and Smucker, 2005b). The natural soil aggregates after few minutes of rotation inside the SAE chambers get a spherical form and then the aggregate surface is in continuous contact with the knurled wall of the erosion chamber. The centrifugal force $\left(C_{F}\right)$ applied on single aggregates by the rotary shaker was calculated as follows (see Fig $2 \mathrm{~b}$ for illustration):

$C_{F}=m(t)\left[R_{S K}+R_{S A E}-R_{a}(t)\right] \omega^{2}$

where $m(t)$ is the mass $(\mathrm{g})$ and $R_{a}(t)$ is the radius of each aggregate that changes with time $t$ as each aggregate is eroded; $R_{S K}$ is the radius of the rotary shaker movement; $R_{S A E}$ is the radius of erosion chamber and $\omega$ is the angular velocity (radian/sec) determined by the rotational speed of rotary shaker $(\mathrm{rpm})$ as follows:

$\omega=2 \pi \times \frac{r p m}{60}$

The rotation friction forces must exceed the natural cohesive and adhesive forces at the soil aggregate surface to remove soil particles from the surface of the rotating aggregate. The erosion rate is then proportional to the difference between external forces and the erosive strength at the aggregate surface.

The frictional force $F$ is proportional to the centrifugal force $C_{F}$ and frictional coefficient $\mu_{F}$ which is a function of the knurled wall roughness and the aggregate surface. The frictional force is defined as:

$$
F=\mu_{F} C_{F}
$$

The concentric layer erosive strength $E_{s}(\mathrm{~N} \cdot \mathrm{g} / \mathrm{min})$ is equivalent to the erosive forces applied to the surface of each soil aggregate layer calculated from the frictional forces applied to the aggregate surface using the mass of soil removed during a given time of applied centrifugal force:

$$
E_{s}=C_{F} /\left[\frac{m\left(t_{n}\right)-m\left(t_{n-1}\right)}{t_{n}-t_{n-1}}\right]
$$

where $m\left(t_{\mathrm{n}}\right)$ and $m\left(t_{\mathrm{n}-1}\right)$ are the masses of the soil aggregate at time $t_{\mathrm{n}}$ and $t_{\mathrm{n}-1}$, respectively. Therefore, these applied external energies could be established and used to compare erosive resistances of intra-aggregate concentric layers among different aggregate size fractions for two soil types subjected to three different management treatments.

\section{Aggregate tensile strength and bulk density measurements}

Tensile strength of single aggregates was measured by crushing tests using a loading frame (Instron 5569, software Merlin). The minimal force applied on an aggregate which caused the breakage was taken as a crushing force. To calculate the aggregate tensile strength following equations were used (Dexter and Kroesbergen, 1985):

$$
T_{s}=0.567 \frac{F}{d^{2}}
$$

$T_{s}$ - tensile strength of the aggregate $(\mathrm{kPa}), F$ - the applied force at failure $(\mathrm{N}), d$ - equivalent diameter of an irregular aggregate (m) defined by

$d=\left[\frac{6 \cdot m}{\Pi \cdot d_{B}}\right]^{1 / 3}$

$m$ is the mass ( $\mathrm{g})$ of the aggregate and $d_{B}$ its bulk density $\left(\mathrm{g} / \mathrm{cm}^{3}\right)$.

The equation gives the equivalent diameter of a sphere having the same mass and density as the tested aggregate.

The density of the bulk soil $\left(d_{B}\right)$ was determined by measuring the mass and the volume of the soil in cylinders taken at the same depth as soil aggregates. The soil aggregates density was determined by coating the single aggregates with paraffin and 
a)

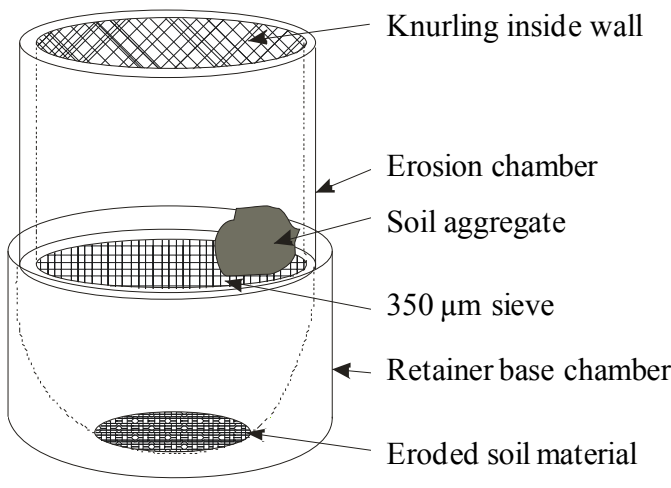

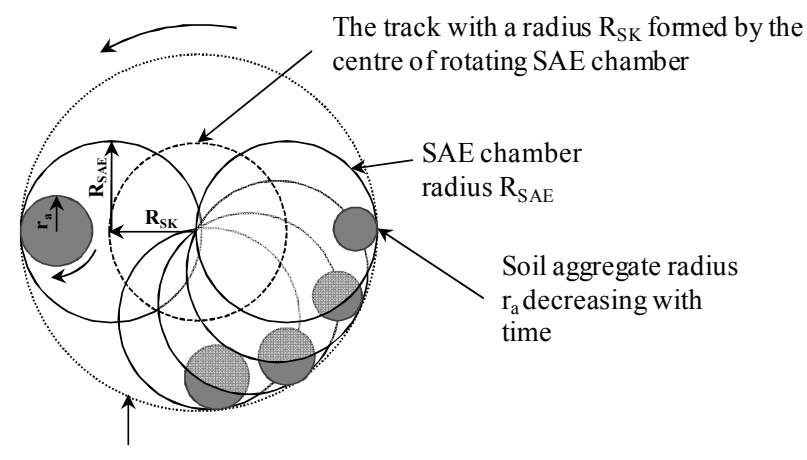

The track of contact points between aggregate and the knurled wall of

b)

SAE chamber

Fig. 2. Sketches of soil aggregate abrasion process: a) soil aggregate erosion (SAE) chamber; b) a rotation motion of soil aggregate in the SAE chamber redrawn from Park and Smucker (2005).

Table 3. Selected values of bulk density $\left(d_{B}\right)\left(\mathrm{g} / \mathrm{cm}^{3}\right)$ of the whole soil, aggregates and the aggregate interior for soils under different tillage type, horizon and aggregate size class $(n=5)$.

\begin{tabular}{|c|c|c|c|c|c|c|c|c|c|c|c|c|}
\hline \multirow{2}{*}{$\begin{array}{c}\text { Soil management } \\
\text { type }\end{array}$} & \multirow{2}{*}{$\begin{array}{c}\text { Soil } \\
\text { horizon }\end{array}$} & \multirow{2}{*}{$\begin{array}{r}\text { Bulk } \\
\text { soil }\end{array}$} & \multicolumn{2}{|c|}{ Whole aggregate } & \multicolumn{2}{|c|}{ Interior } & \multicolumn{2}{|c|}{ Whole aggregate } & \multicolumn{2}{|c|}{ Interior } & \multicolumn{2}{|c|}{ Whole aggregate } \\
\hline & & & $12-8$ & $+/-$ & $12-8$ & $+1-$ & $8-5$ & $+/-$ & $8-5$ & $+1-$ & $5-2$ & $+1-$ \\
\hline \multirow{3}{*}{ Conventional tillage } & Ap 1 & 1.38 & 1.54 & 0.02 & 1.98 & 0.03 & 1.57 & 0.02 & 2.05 & 0.04 & 2.19 & 0.06 \\
\hline & Ap2 & 1.61 & 1.63 & 0.03 & 1.89 & 0.08 & 1.71 & 0.02 & 1.86 & 0.03 & 2.22 & 0.06 \\
\hline & Sw-M & 1.54 & 1.67 & 0.01 & 1.87 & 0.06 & 1.71 & 0.00 & 1.88 & 0.01 & 2.09 & 0.08 \\
\hline \multirow{3}{*}{$\begin{array}{l}\text { Reduced } \\
\text { tillage }\end{array}$} & Ap & 1.49 & 1.66 & 0.04 & 2.13 & 0.09 & 1.72 & 0.02 & 2.20 & 0.21 & 2.19 & 0.11 \\
\hline & $\mathrm{rAp}$ & 1.57 & 1.70 & 0.02 & 1.96 & 0.05 & 1.74 & 0.02 & 1.96 & 0.10 & 2.09 & 0.06 \\
\hline & $\mathrm{Bt}$ & 1.50 & 1.77 & 0.03 & 2.00 & 0.04 & 1.75 & 0.03 & 2.00 & 0.06 & 2.32 & 0.05 \\
\hline \multirow{3}{*}{ No tillage } & $\mathrm{Ah}$ & n.d. & 1.50 & 0.01 & 1.71 & 0.09 & 1.59 & 0.02 & 1.68 & 0.05 & 2.12 & 0.10 \\
\hline & $\mathrm{rAp}$ & n.d. & 1.57 & 0.01 & 1.69 & 0.11 & 1.68 & 0.03 & 1.83 & 0.05 & 2.13 & 0.08 \\
\hline & Sw-M & n.d. & 1.66 & 0.01 & 1.76 & 0.15 & 1.61 & 0.03 & 1.73 & 0.05 & 2.12 & 0.06 \\
\hline
\end{tabular}

measuring their volume in distilled water. The bulk density of the aggregates after abrasion was determined by measuring the mass and the diameter of the spherically shaped aggregates with calliper after defined abrasion time.

\section{STATISTICAL ANALYSIS}

The statistical calculation of the data was based on the arithmetic means and standard error of the mean (+/-) considering the size of aggregates, soil depth and management system. The comparisons confidence test for the bulk density $(n=10)$ and tensile strength $(\mathrm{n}=20)$ were conducted using one-way (no blocking) ANOVA statistical analyses with Tukey's multivariate test at the significance level of $95 \%$. The calculations of the erosive strength for different aggregate regions were done on 5 replicates for each aggregate size. The regression analysis between $E_{s}$ and \% peeled mass was conducted on aggregates from the same size class, depth and vegetation. The best fit for this relation can be expressed by the equation:

$E_{s}=a e^{b X}$

where $X$ is \% of peeled mass from the aggregate exterior to the interior (the location of the concentric layer within the aggregates), $\mathrm{a}$ and $\mathrm{b}$ are the regression constants of the exponential equation. The values of the erosive strength of exterior, transitional, interior region and the whole aggregate were calculated using the integration form of $E_{s}=\int a e^{b x} d x$.

\section{RESULTS}

\section{Bulk density and intra-aggregate porosity}

The results of bulk density $\left(d_{B}\right)$ measurements for bulk soil, whole aggregates of different size and the interior of the aggregate show pronounced differences for soils under different tillage type (Table 3 ). In general, the bulk soils show lower $d_{B}$ than the aggregates, and smaller aggregates have higher bulk density than the larger ones. For example the $d_{B}$ of the bulk soil from reduced tillage in the Ap horizon is $10 \%$ lower than for the $12-8 \mathrm{~mm}$ aggregates; the 5-2 mm aggregates have $20 \%$ higher $d_{B}$ values than the $8-5 \mathrm{~mm}$ aggregates. The bulk density for the whole soil as well as for different size aggregates show the lowest values in the top horizons and increase with depth. The aggregate bulk density is not only affected by soil depth and aggregate size but also by tillage practices. In soil under reduced tillage the bulk density of whole aggregates is higher than soils under conventional and no tillage and interior of aggregates under conventional and reduced tillage have much higher $d_{B}$ than the whole aggregates. In soils under no tillage the 
differences between the whole aggregates and the aggregate interiors are much less pronounced.

\section{Tensile strength of aggregates of different size}

The tensile strength of air-dried soil aggregates presented in Figure 3 ranges show significant variations between the top and subsoil horizons in the soils under conventional and reduced tillage. Aggregates from Ap horizons have generally lower tensile strength in comparison to the subsoil horizons and the difference is most pronounced in soils under conventional and reduced tillage. The tensile strength of aggregates in soil under no tillage is relatively uniform among different size aggregates and soil horizons. The tensile strength is also a function of aggregate size. Most of larger aggregates show lower values of $T_{s}$ than smaller ones, but the differences are not statistically significant.

\section{Abrasion time and erosive strength of single aggregates}

The time required to abrade soil material from aggregates differ to a high extent (Figure 4). Time required to abrade $75 \%$ of aggregate mass varies from $120 \mathrm{~min}$ (2 hours) to 1000 (19 hours) depending on the tillage system, horizon and size of the aggregates. Generally, the aggregates from the subsoil required more time for the abrasion than those from the topsoil. The shortest abrasion time was required for aggregates from soils under conventional tillage in contrast to the aggregates from soil under reduced and no tillage. The difference between abrasion time of larger and smaller aggregates is relatively small and not statistically significant. Because applied centrifugal forces change when the aggregate is peeled, the erosion time can be only used for quick estimation of aggregate strength and erosive strength values presented below are more representative.

The erosive strength $\left(E_{s}\right)$ of single aggregates correspond with the abrasion rates and show low values in the exterior regions, but increase in the aggregate transitional and interior regions (Figure 5). The empirical values of erosive strength of single aggregates are fitted with exponential curves and the parameters and correlation values are presented in the Table 4.

The highest erosive strengths and the higher differences between aggregate exterior and interior regions have the aggregates derived from the subsoil horizons, while much lower erosive strength show the aggregates from upper soil horizons.
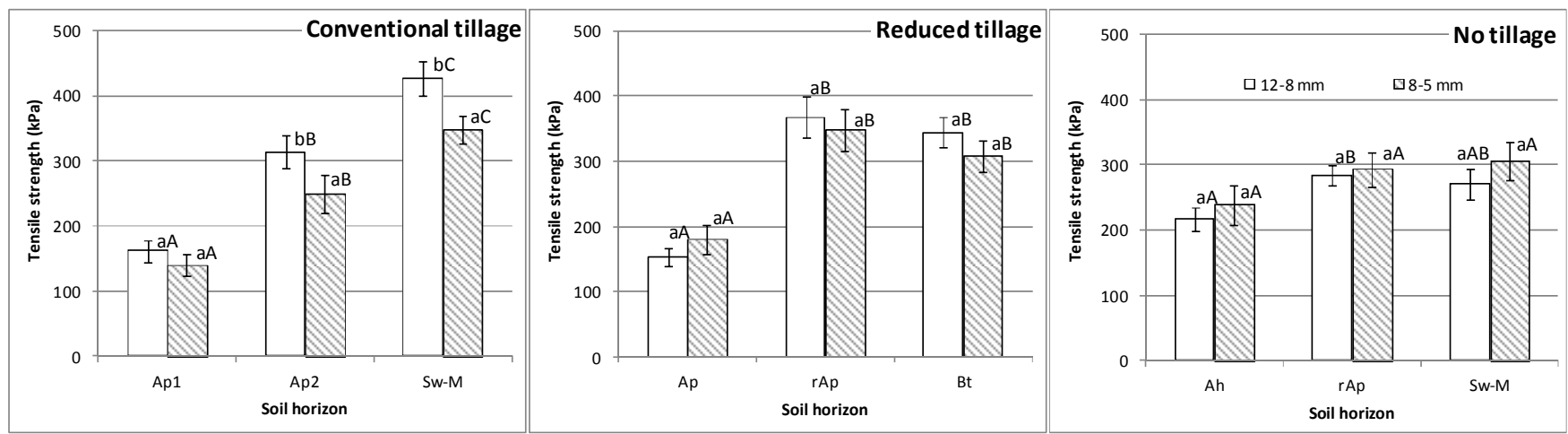

Fig. 3. Tensile strength of aggregates of different size classes and soil horizon from soils under different tillage $(n=20)$. Varying lowercase letters $(a, b, c)$ identify significant differences among aggregate size classes $(p=0.05)$ within the same soil horizon and tillage type, the capital letters (A, B, C) identify statistically significant differences between the same aggregate size class but different soil horizon $(\mathrm{p}=0.05)$.

Table 4. Fitted relation expressed by $\mathrm{R}^{2}$ between erosive strength $\left(E_{s}\right)$ and peeled mass $(\%)$ for aggregates under different tillage type, soil horizons and aggregate size classes $(\mathrm{n}=5)$ at statistical significance level of $0.01(*)$ or $0.001(* *)$.

\begin{tabular}{|c|c|c|c|c|c|c|c|}
\hline \multirow{2}{*}{ Tillage type } & \multirow{2}{*}{$\begin{array}{c}\text { Soil } \\
\text { horizon }\end{array}$} & \multicolumn{3}{|c|}{ Aggregate size $12-8 \mathrm{~mm}$} & \multicolumn{3}{|c|}{ Aggregate size $8-5 \mathrm{~mm}$} \\
\hline & & $\mathbf{a}$ & b & $\mathbf{R}^{2}$ & $\mathbf{a}$ & b & $\mathbf{R}^{2}$ \\
\hline \multirow{3}{*}{$\begin{array}{l}\text { Conventional } \\
\text { tillage }\end{array}$} & Ap 1 & 2.54 & 1.82 & $0.25 * *$ & 0.9 & 2.01 & $0.62 * *$ \\
\hline & Ap2 & 2.36 & 1.7 & $0.52 * *$ & 1.99 & 1.71 & $0.43 * *$ \\
\hline & $\mathrm{Sw}-\mathrm{M}$ & 1.76 & 1.3 & $0.39 * *$ & 2.62 & 1.89 & $0.3^{* *}$ \\
\hline \multirow{3}{*}{$\begin{array}{l}\text { Reduced } \\
\text { tillage }\end{array}$} & Ap & 4.78 & 1.04 & $0.16 *$ & 1.36 & 2.44 & $0.53 * *$ \\
\hline & $\mathrm{rAp}$ & 5.97 & 2.02 & $0.68 * *$ & 2.16 & 2.52 & $0.57 * *$ \\
\hline & $\mathrm{Bt}$ & 3.58 & 2.73 & $0.62 * *$ & 2.8 & 3.14 & $0.6 * *$ \\
\hline \multirow{3}{*}{ No tillage } & $\mathrm{Ah}$ & 2.36 & 1.89 & $0.51 * *$ & 2.91 & 1.27 & $0.57 * *$ \\
\hline & $\mathrm{rAp}$ & 5.15 & 0.66 & $0.13 *$ & 4.93 & 1.63 & $0.38 * *$ \\
\hline & $\mathrm{Sw}-\mathrm{M}$ & 3.99 & 1.88 & $0.33 * *$ & 3.61 & 2.22 & $0.39 *$ \\
\hline
\end{tabular}




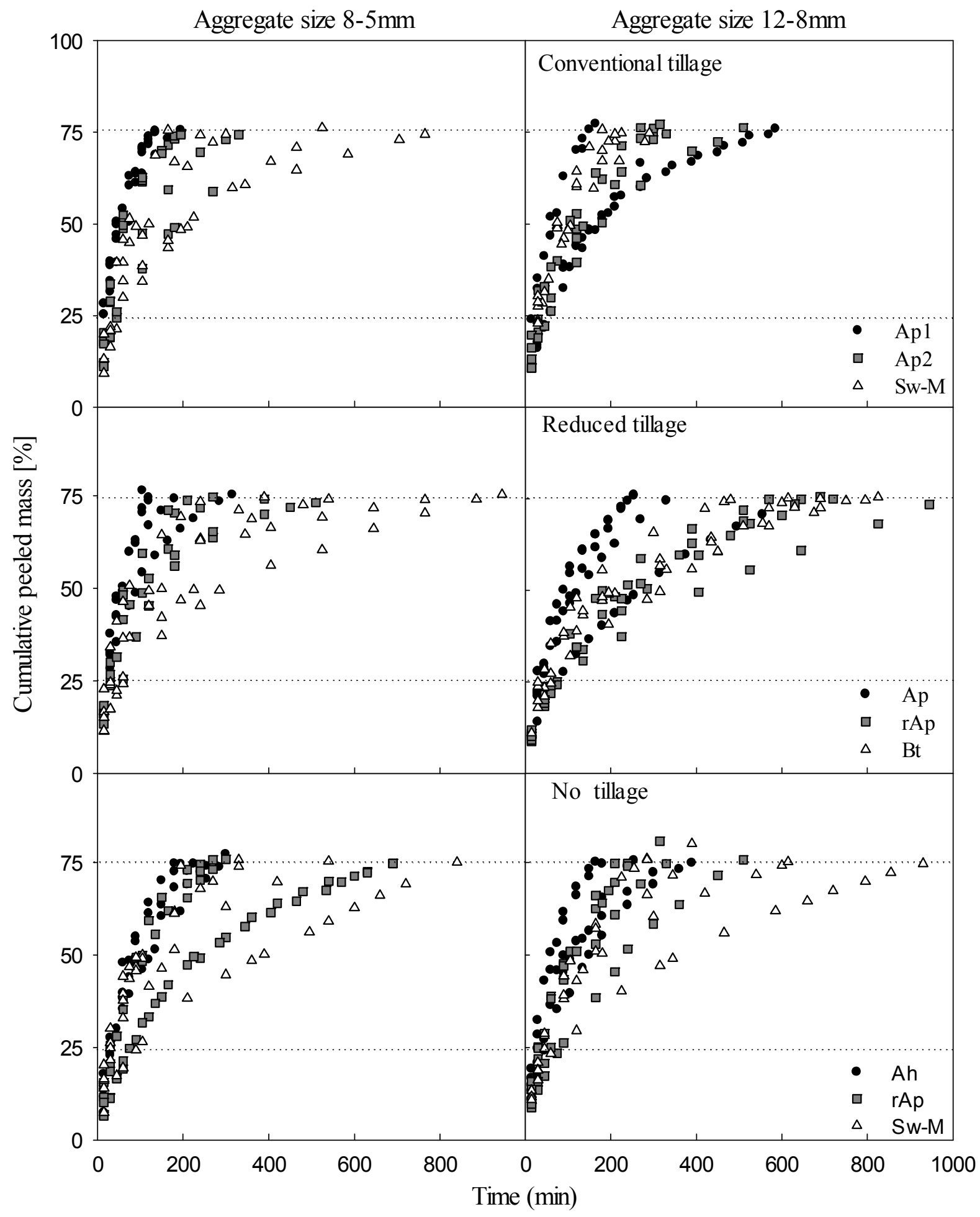

Fig. 4. Abrasion time of soil aggregates from two aggregate size classes and three horizons from soils under different tillage type $(n=5)$.

The differences in the erosive strength of aggregates between horizons are much more pronounced in soil under conventional and reduced tillage, while the aggregates derived from no tillage soil show lower variability between aggregate sizes, regions and horizons. In addition, the aggregates derived from soil under reduced tillage show much steeper exponential increase of erosive strength in transitional region than the aggregates under other types of tillage.
Relationship between tensile and erosive strength, bulk density and organic carbon content

The erosive $\left(E_{s}\right)$ and the tensile strength $\left(T_{s}\right)$ of aggregates show very strong positive correlation for aggregates of $8-5 \mathrm{~mm}$ size and 12-8 $\mathrm{mm}$ size under reduced tillage (Table 5) while strong negative correlation exist for aggregates of 12-8 $\mathrm{mm}$ size under conventional tillage. Bulk density of aggregates on the 


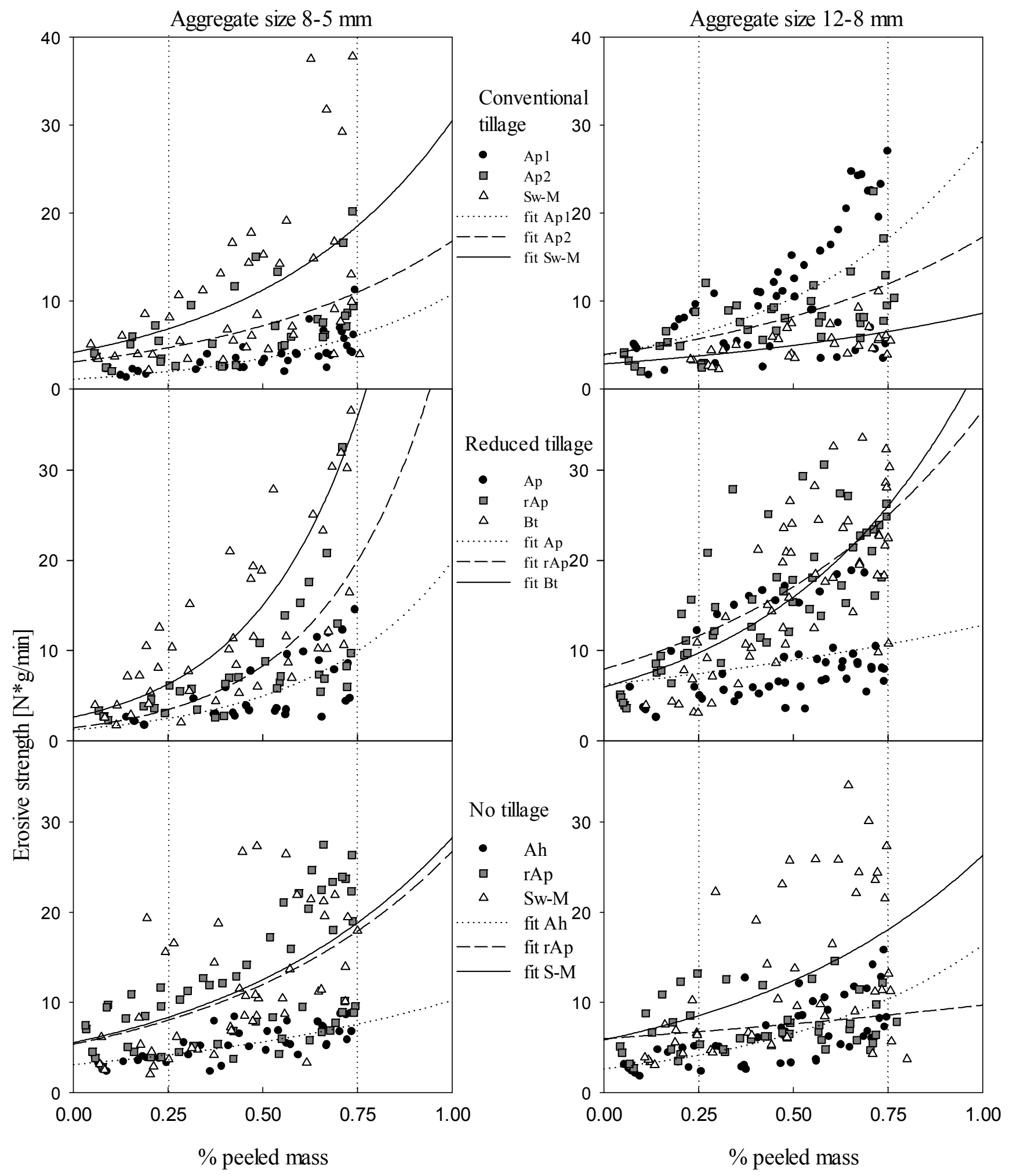

Fig. 5. Erosive strength of aggregates as a function of $\%$ of peeled mass for two aggregate size classes and three soil horizons derived from soils under different tillage type $(\mathrm{n}=5)$.

other hand show strong positive correlation for soil under conventional and reduced tillage while for soil under no-tillage the correlation is relatively weak.

The distribution of organic carbon and hydrophobic C-H carbon groups derived from each aggregate layers show mostly negative correlations with the erosive strength of single concentric layers from soil aggregates under different tillage type, horizons and aggregate size (Table 6). The exceptional are the aggregates derived from soil under conventional tillage in the Ap1 horizon which show very weak correlations between the total organic carbon and the $E_{s}$. 
Table 5. Pearson correlation coefficients between the tensile strength $\left(T_{s}\right)$ and the erosive strength $\left(E_{s}\right)$, bulk density $\left(d_{B}\right)$ of different sizeclass aggregates derived from soils under different tillage type at the significance level of $0.01(*)$ and $0.001(* *)(\mathrm{n}=5)$.

\begin{tabular}{ccccccc}
\hline & \multicolumn{2}{c}{ Aggregate size 12-8mm } & \multicolumn{3}{c}{ Aggregate size 8-5mm } \\
\hline \hline & $\begin{array}{c}\text { Conventional } \\
\text { tillage }\end{array}$ & $\begin{array}{c}\text { Reduced } \\
\text { tillage }\end{array}$ & No tillage & $\begin{array}{c}\text { Conventional } \\
\text { tillage }\end{array}$ & $\begin{array}{c}\text { Reduced } \\
\text { tillage }\end{array}$ & No tillage \\
\hline & & $\mathrm{T}_{\mathrm{s}}$ & & & $\mathrm{T}_{\mathrm{s}}$ & \\
\hline $\mathrm{Es}$ & $-0.99^{* *}$ & $0.99^{* *}$ & $-0.21^{*}$ & $0.99^{* *}$ & $0.64^{* *}$ & $0.97^{* *}$ \\
$\mathrm{~dB}$ & $0.99^{* *}$ & $0.74^{* *}$ & $0.27^{*}$ & $0.88^{* *}$ & $0.74^{* *}$ & $0.24^{*}$ \\
\hline
\end{tabular}

Table 6. Pearson correlation coefficients between erosive strength $\left(E_{s}\right)$, the organic carbon $\left(\mathrm{C}_{\text {org }}\right)$ and hydrophobic C-H groups content in aggregates derived from soils under different tillage, soil horizon and aggregate size class at the statistical significance level $0.01(*)$ or $0.001(* *)$ $(\mathrm{n}=5)$.

\begin{tabular}{|c|c|c|c|c|c|c|}
\hline \multirow{2}{*}{ Tillage type } & \multirow{2}{*}{$\begin{array}{c}\text { Soil } \\
\text { horizon }\end{array}$} & & \multicolumn{2}{|c|}{ Corg content } & \multicolumn{2}{|c|}{ Hydrophobic carbon groups $(\mathrm{C}-\mathrm{H})$} \\
\hline & & & $12-8 \mathrm{~mm}$ & $8-5 \mathrm{~mm}$ & $12-8 \mathrm{~mm}$ & $8-5 \mathrm{~mm}$ \\
\hline \multirow{3}{*}{$\begin{array}{l}\text { Conventional } \\
\text { tillage }\end{array}$} & Ap1 & & $-0.21^{*}$ & $0.49^{*}$ & $-0.66^{* *}$ & $-0.68^{* *}$ \\
\hline & Ap 2 & $\mathrm{E}_{\mathrm{s}}$ & $-0.96^{* *}$ & $-0.98 * *$ & $-1.0 * *$ & $-0.86^{* *}$ \\
\hline & $\mathrm{Sw}-\mathrm{M}$ & & $-0.71 * *$ & $-0.98 * *$ & $-0.94 * *$ & $-0.31 *$ \\
\hline \multirow{3}{*}{ Reduced tillage } & Ap & & $-0.79 * *$ & $-0.24^{*}$ & $-0.91 * *$ & $-0.93 * *$ \\
\hline & $\mathrm{rAp}$ & $\mathrm{E}_{\mathrm{s}}$ & $-0.98 * *$ & $-0.79 * *$ & $-1.0 * *$ & $-0.82 * *$ \\
\hline & $\mathrm{Bt}$ & & $-0.44 *$ & $-0.15^{*}$ & n.d. & n.d. \\
\hline \multirow{3}{*}{ No tillage } & $\mathrm{Ah}$ & & $-0.61 * *$ & $-0.81 * *$ & $0.37^{*}$ & $-0.15^{*}$ \\
\hline & $\mathrm{rAp}$ & $\mathrm{E}_{\mathrm{s}}$ & $-0.09 *$ & $-0.91 * *$ & $-0.72 * *$ & $-0.97 * *$ \\
\hline & $\mathrm{Sw}-\mathrm{M}$ & & $-0.93 * *$ & $-0.91 * *$ & $-0.72 * *$ & $-0.97 * *$ \\
\hline
\end{tabular}

\section{DISCUSSION}

Different types of soil management and tillage have been recognised to have strong effects on soil structure and ability to withstand the stresses applied on soils. Reduced tillage practices have been recognised to be beneficial for soil health, however, the effect is not immediate and may take several years if not decades for the soil to recover from repeated tillage disturbance in order to rich an equilibrium. The overall strength of the soil is related to soil structure stability and aggregate strength, which in turn depends on the arrangement of soil particles, geometries of air filled pores, strength of mineral-organic bonds and other cementing agents between soil particles (Horn and Smucker, 2005; Kay and Dexter, 1992). The bulk density of the whole soil as well as aggregates is important for the soil strength. Typically lower bulk densities are found in the bulk soil than in aggregates due to the presence of larger macropores between soil aggregates. The porosity of aggregates is usually lower therefore the aggregate bulk density is higher. In our study the soil under conventional tillage had very low bulk density values of the bulk soil and aggregates of larger size class (12-8 mm and $8-5 \mathrm{~mm}$ ). On the other hand, the bulk density of the interior areas and the small aggregates was much higher and relatively comparable with the $d_{B}$ of interior areas and small aggregates of soils under reduced and no tillage. The fact that the $d_{B}$ of conventionally tilled soils was so variable identifies that the tillage practices cause disruption of mainly larger aggregates or the exterior areas of aggregates while the interiors remain less or not affected. Soil structure under reduced tillage still remain highly affected by previous conventional tillage practices which were changed to reduced tillage only 6 years earlier. The soil aggregates under no-tillage show the most uniform bulk density values between the aggregates of different size and aggregate region and therefore can be considered as most structurally stable and provide healthy conditions for plant growth, hydraulic conductivity and gas exchange (Kodešová et al., 2009b).

The aggregate tensile strength results tend to have similar trends as the bulk density, but the effect of different soil management is even more pronounced. The low tensile strength of soil aggregates is most evident in top horizons of soils under conventional and reduced tillage. In soil aggregates under conventional tillage the strength of aggregates in the Ap2 horizon is higher than the Ap1 horizon, but the highest values are in Sw-M horizon. Such high aggregate strength maybe due to the slightly higher silt contents which could have very strong cementing effect especially under dry conditions (Kay and Angers, 2000). The aggregates in the subsoil may also have been compacted by the repeated tillage and usage of the heavy machinery (Horn et al., 2004), but the aggregate $d_{B}$ similar to the $d_{B}$ of other horizons does not confirm this hypothesis. The soil aggregates under the reduced tillage show increase strength for the rAp and Bt horizon which identifies that the soil structure is more stable at depth where disruptive forces of tillage are less effective. The uniform aggregate strength under no tillage identifies that the soil structure is in equilibrium at all depths and the soil structure reformation are mainly due to soil moisture and temperature 
fluctuations. Other studies report similar results in relation to the tillage practices. The most destructive for soil structure are the tillage practices which cause the breakage of natural arrangement of soil particles in aggregates (Hadas, 1990; Six et al., 2000) and bring the subsurface soil to the surface and then expose it to wet-dry and freeze-thaw cycles or rain drop impact (Beare et al., 1994; Paustian et al., 1997). Such applied stresses cause disturbance in soil particles, especially clay particles which are displaced from their former equilibrium positions of low free energy and moved to a new position of higher free energy (Dexter, 1988).

The aggregate erosive strength, which provides useful information about the binding of soil particles within aggregates, is much lower for aggregates from soils under intensive tillage than one for the less or no tilled soils. The low erosive strength of aggregates under conventional tillage is probably due to the repeated disruption of soil structure by cultivation and repeated breakdown of aggregates. This may suggest that the less disturbed is the soil, the stronger is the erosive strength, however, in case of the aggregates from soils under reduced and notillage relatively small difference can be detected. More substantial differences in erosive strength are between the aggregates from topsoil and subsoil. The reason for such tendency may lay in the cementing forces in these aggregates. Soil organic carbon and hydrophobic $\mathrm{C}-\mathrm{H}$ groups have been considered as main binding agents for the soil particles in these soils. The fact that the distribution of soil carbon and specific hydrophobic C$\mathrm{H}$ groups have been identified for each particular soil aggregate region presented in the study of Urbanek et al. (2007) makes the comparison of the erosion strength even more reliable. The correlations between the erosive strength, organic carbon content and hydrophobic carbon groups are negative. This result is in opposition to many other studies identifying that organic matter has stabilising effect on soil structure (Capriel et al., 1990; Chenu et al., 2000). The explanation for such result suggests that the dry organic matter may have the opposite effect to moist organic matter. Organic matter in soils under dry condition may make soils more prone to structural disturbance and erosion than soil under moist condition. Perfect et al. (1995) reported that the organic matter can be positively related with the tensile strength of air-dry aggregates for some clayey soils, while in soil aggregates with coarser texture the content of organic matter can have even a negative effect. Dexter (1988) underlined the importance of particle-particle bonds for soil strength and suggested that as the soil dries, the tension in the retreating menisci can generate sufficient force to displace the intervening water molecules and so produce much closer contact between mineral particles. Any ion or other species adjacent to such a contact is able to bond both involved particles. Where such double-bonding can occur the free energy will be lower than that for the same species adsorbed on a plane or convex surface. Consequently, these species tend to diffuse across the particle surfaces towards the regions of contact in response to the gradients of free energy. A wide range of ions, molecules, colloids and amorphous gels can diffuse in this way towards the regions of particle-particle contact where they can strengthen or cement the bonds.

The concept of aggregates forming concentric layers with different physical and chemical gradient presented in this and previous studies (e.g. Jasinska et al., 2006; Park and Smucker, 2005a; Urbanek et al., 2007, 2011) seems more pronounced in aggregates under no-tillage where natural rather that human processes are forming the soil structure. Strong positive correlation between the tensile and erosive strength of soil aggregates detected only for 8-5 mm aggregates for all tillage types, how- ever, in case of larger aggregates under conventional tillage the correlation was negative. This may confirm the speculations that the tillage destroys mainly larger aggregates while the smaller once remain less affected. It may also suggest that larger aggregates are formed from binding of the smaller aggregates and only the smaller aggregates develop physico-chemical gradients.

The results suggest that in case of $8-5 \mathrm{~mm}$ and possibly smaller aggregates the tensile strength is controlled by the sum of the concentric layer strengths (Park and Smucker, 2005b).

The information about the erosive strength gives a new insight about the soil structure stability. The internal strength correlated with higher bulk density and consequently lower porosity of soil aggregates may have consequences for the accessibility of soil microorganisms to the organic matter physically protected in soil aggregates.

Although the erosive strength technique cannot be considered as a replacement for the tensile aggregate strength it creates a new approach to look at the soil aggregation. The tensile strength maybe more relevant in terms of the disturbance of the soil by mechanical compaction, wheeling of heavy machinery etc., the erosive strength may be more useful for the degradation of the soil by water and wind erosion. The top layer of the soil is especially exposed to this kind of disturbance and bare soil maybe especially prone to this kind of degradation.

\section{CONCLUSIONS}

The measurement of mechanical properties of soil aggregates from different soil managements and soil horizons show that the type of tillage practices has a big effect on aggregate strength. The aggregates from the top horizons in soils under conventional tillage and reduced tillage are the most affected by tillage practices which is reflected in very high bulk densities of small aggregates and the interior of larger aggregates while the $d_{B}$ of bulk soil remains very low. The disruptive effect of tillage is also visible in very low tensile and erosive strength of aggregates from the top horizons. Such results suggest that the cultivation practices are the most disruptive for larger aggregates or the exteriors of larger aggregates. Large macropores between the aggregates reduce the structure stability of the bulk soil and may promote the preferential flow of water and solutes.

The study shows that the soil aggregates from soil under no tillage have very uniform aggregate strength and bulk density providing higher structural stability more consistent water distribution in the soil.

Tensile strength of soil aggregates correlates well with the erosive strength suggesting that tensile strength of the aggregate is controlled by the sum of the concentric layer strengths.

The study shows a negative correlation between the organic carbon content and the erosive strength suggesting that cementing properties of soil organic carbon and hydrophobic $\mathrm{C}-\mathrm{H}$ groups maybe lost when soil is dry.

The technique to determine the erosive strength of aggregates is not meant to provide a replacement to traditional methods of aggregates strength, but it provides a very useful information about the binding of soil particles within soil aggregates and maybe very useful for assessing the soil degradation by water and wind erosion.

Acknowledgements. This study was supported by a grant from the German Research Foundation (DFG) in the priority programme 1090. The first author thanks the Royal Society for the support under the Dorothy Hodgkin Fellowship and the two 
independent reviewers for useful comments on the original version of the manuscript.

\section{REFERENCES}

Abiven, S., Menasseri, S., Chenu, C., 2009. The effects of organic inputs over time on soil aggregate stability - A literature analysis. Soil Biology and Biochemistry, 41, 1-12.

Ananyeva, K., Wang, W., Smucker, A.J.M., Rivers, M.L., Kravchenko, A.N., 2013. Can intra-aggregate pore structures affect the aggregate's effectiveness in protecting carbon? Soil Biology and Biochemistry, 57, 868-875.

Bachmann, J. Guggenberger, G., Baumgartl, T., Ellerbrock, R.H., Urbanek, E., Goebel, M.-O., Kaiser, K., Horn, R., Fischer, W.R., 2008. Physical carbon-sequestration mechanisms under special consideration of soil wettability. Journal of Plant Nutrition and Soil Science, 171, 14-26.

Beare, M.H., Cabrera, M.L., Hendrix, F.P., 1994. Aggregateprotected and unprotected organic matter pools in conventional and no-tillage soils. Soil Science Society of America Journal, 58, 787-795.

Bronick, C.J., Lal, R., 2005. Soil structure and management: a review. Geoderma, 124, 3-22.

Capriel, P., Beck, T., Borchert, H., Härter, P., 1990. Relationship between soil aliphatic fraction extracted with supercritical hexane, soil microbial biomass and soil aggregate stability. Soil Science Society of America Journal, 54, 415-420.

Chenu, C., Le Bissonnais, Y., Arrouays, D., 2000. Organic matter influence on clay wettability and soil aggregate stability. Soil Science Society of America Journal, 64, 1479-1486.

Dexter, A.R., 1988. Advances in characterization of soil structure. Soil and Tillage Research, 11, 199-238.

Dexter, A.R., Kroesbergen, B., 1985. Methodology for determination of tensile strength of soil aggregates. Journal of Agricultural Engineering Research / publ. for the British Society for Research in Agricultural Engineering, 31, 139-147.

Dutarte, P., Bartoli, F., Andreux, F., Portal, J.M., Ange, A., 1993. Influence of content and nature of organic matter on the structure of some sandy soils from West Africa. Geoderma, 56, 459-478.

Hadas, A., 1990. Directional strength in aggregates as affected by aggregate volume and by a wet/dry cycle. Journal of Soil Science, 41, 85-93.

Holland, J.M., 2004. The environmental consequences of adopting conservation tillage in Europe: reviewing the evidence. Agriculture, Ecosystems \& Environment, 103, 1-25.

Horn, R., Smucker, A.J.M., 2005. Structure formation and its consequences for gas and water transport in unsaturated arable and forest soils. Soil and Tillage Research, 82, 5-14.

Horn, R., Vossbrink, J., Becker, S., 2004. Modern forestry vehicles and their impacts on soil physical properties. Soil and Tillage Research, 79, 207-219.

Jasinska, E., Wetzel, H., Baumgartl, T., Horn, R., 2006. Heterogeneity of physico-chemical properties in structured soils and its consequences. Pedosphere, 16, 284-296.

Kay, B.D., Angers, A.D., 2000. Soil structure. In: Sumner, M.E. (Ed.): Handbook of Soil Science. CRC Press, Boca Raton.

Kay, B.D., Dexter, A., 1992. The influence of dispersible clay and wetting/drying cycles on the tensile strength of a redbrown earth. Australian Journal of Soil Research, 30, 297-310.

Kodešová, R., Rohošková, M., Žigová, A., 2009a. Comparison of aggregate stability within six soil profiles under conventional tillage using various laboratory tests. Biologia, $64,550-554$.
Kodešová, R., Vignozzi, N., Rohošková, M., Hájková, T., Kočárek, M., Pagliai, M., Kozák, J., Šimůnek, J., 2009b. Impact of varying soil structure on transport processes in different diagnostic horizons of three soil types. Journal of Contaminant Hydrology, 104, 1-4, 107-125.

Lal, R., 2003. Global potential of soil carbon sequestration to mitigate the greenhouse effect. Critical Reviews in Plant Sciences, 22, 151-184.

Park, E.-J., Smucker, A., 2005a. Dynamics of carbon sequestered in concentric layers of soil macroaggregates. Korean Journal of Ecology, 28, 181-188.

Park, E.-J., Smucker, A.J.M., 2005b. Erosive strengths of concentric regions within soil macroaggregates. Soil Science Society of America Journal, 69, 1912-1921.

Park, E.-J., Smucker, A.J.M., 2005c. Saturated hydraulic conductivity and porosity within macroaggregates modified by tillage. Soil Science Society of America Journal, 69, 38-45.

Paustian, K., Collins, H.P., Paul, E.A., 1997. Management controls on soil carbon. In: Paul, E.A. (Ed.): Soil organic matter in temperate agroecosystems: Long-term experiments in North America. CRC Press, Boca Raton, FL, pp. 15-49.

Perfect, E., Kay, B.D., da Silva, A.P., 1995. Influence of soil properties on the statistical characterization of dry aggregate strength. Soil Science Society of America Journal, 59, 532537.

Piccolo, A., Mbagwu, J., S.C., 1999. Role of hydrophobic components of soil organic matter in soil aggregate stability. Soil Science Society of America Journal, 63, 1801-1810.

Santos, D., Murphy, S.L.S., Taubner, H., Smucker, A.J.M., Horn, R., 1997. Uniform separation of concentric surface layers from soil aggregates. Soil Science Society of America Journal, 61, 720-724.

Six, J., Paustian, K., Elliott, E.T., Combrink, C., 2000. Soil Structure and organic matter: I Distribution of aggregate-size classes and aggregate-associated carbon. Soil Science Society of America Journal, 64, 681-689.

Tisdall, J.M., Oades, J.M., 1982. Organic matter and waterstable aggregates in soils. Journal of Soil Science, 33, 141163.

Urbanek, E., Hallett, P., Feeney, D., Horn, R., 2007. Water repellency and distribution of hydrophilic and hydrophobic compounds in soil aggregates from different tillage systems. Geoderma, 140, 147-155.

Urbanek, E., Smucker, A., Horn, R., 2011. Total and fresh organic carbon distribution in aggregate size classes and single aggregate regions using natural $13 \mathrm{C} / 12 \mathrm{C}$ tracer. Geoderma, 164, 164-171.

von Lützow, M., Kogel-Knabner, I., Ekschmitt, K., Matzner, E., Guggenberger, G., Marschner, B., Flessa, H., 2006. Stabilization of organic matter in temperate soils: mechanisms and their relevance under different soil conditions - a review. European Journal of Soil Science, 57, 426-445.

Wang, W., Kravchenko, A.N., Smucker, A.J.M., Liang, W., Rivers, M.L., 2012. Intra-aggregate pore characteristics: Xray computed microtomography analysis. Soil Science of America Journal, 76, 1159-1171.

WRB, 2006. World reference base for soil resources 2006. 2nd edition. World Soil Resources Reports No. 103. FAO, Rome. $128 \mathrm{pp}$

Received 23 June 2014

Accepted 12 August 2014 